Artigos

\title{
Construção Identitária no Processo de Aprendizagem de Língua e Cultura em Autobiografia de Imigrante
} Identity Construction in the Process of Learning Language and Culture in an Immigrant Autobiography

\author{
Tania Regina de Souza Romero' \\ Allysson Augusto S. Casais ${ }^{2}$
}

\section{RESUMO}

Este artigo discute o processo de construção identitária do docente de línguas, partindo de autobiografia de um professor de inglês, ex-imigrante nos E.U.A. Dentro de enquadre qualitativo, enfoca embates pessoais vivenciados durante a aprendizagem do inglês e de inserção na cultura estadunidense, bem como significações construídas em experiências docentes iniciais. Sustentam o estudo conceituações sobre a intricada natureza da identidade do professor de línguas (Barkhuizen, 2017) e o papel da agência para o desenvolvimento pessoal (Lantolfe Thorne, 2006). A narrativa é, ainda, analisada linguisticamente com base no Sistema de Avaliatividade. Resultados apontam o protagonismo das emoções na constituição identitária.

Palavras-chave: Identidade do docente de línguas; agência; autobiografias; avaliatividade.

1. Universidade Federal de Lavras. Lavras, Minas Gerais - Brasil. http://orcid.org/00000001-7876-8907. E-mail: taniaromero@ufla.br

2. Universidade Federal Fluminense. Niterói, Rio de Janeiro - Brasil. http://orcid.org/00000003-3690-1532. E-mail: allyssoncasais@hotmail.com 


\begin{abstract}
This article discusses the construction of language teachers identity, based on an autobiography written by a teacher of English, former immigrant in the U.S.A. The focus, through qualitative analysis, is on personal struggles experienced while learning English and trying to fit in the foreign culture, and the meanings construed in initial teaching experiences. Discussions on the intricate nature of language teacher identity (Barkhuizen, 2017) and the role of agency in personal development (Lantolf and Thorne, 2006) underlie the study. The narrative is also linguistically analyzed according to the system of Appraisal. Results reveal the relevance of emotions in identity development.
\end{abstract}

Keywords: Language teacher identity; agency; autobiographies; appraisal.

\title{
Introdução
}

O papel de narrativas autobiográficas tem ocupado posição de destaque na formação de professores por seu potencial de trazer à tona indícios de como significados ${ }^{3}$ que tecemos ao longo da vida foram sendo construídos. Por meio da história que contamos de nós mesmos não só nos reconhecemos, como conseguimos pontuar acontecimentos especialmente relevantes que marcaram nossas vidas, pessoas que nos serviram como exemplo ou exerceram influência em nossas decisões pessoais, profissionais e/ou acadêmicas. Assim, as autobiografias possibilitam o mapeamento do processo de constituição identitária, oferecendo pistas de como foram sendo conceituados princípios que resultam em modos de se entender o mundo e os outros, bem como modos de se agir socialmente.

No escopo de formação do docente de línguas, autobiografias são especialmente relevantes por nos permitirem entender a construção identitária do (futuro) profissional, geralmente pontuada por sentimentos contraditórios de desejo de pertencimento e de perda de origem

3. O conceito de significados é de grande relevância na abordagem sociocultural vygotskyana. Refere-se a sentidos e significados construídos social e culturalmente pelo indivíduo e compartilhados na cultura em que está inserido, podendo se alterar, dependendo das interações ideológicas e psicológicas com as quais a pessoa se envolver ao longo de suas vivências (Oliveira e Rego, 2003). 
(Kramsch, 2012). A linguagem gerada no processo de elaboração da autobiografia tem o potencial de desvelar significados tecidos no percurso singular da vida de cada um e, conforme argumenta Norton (2012: 4), a linguagem desempenha um papel central na relação entre o indivíduo e o social, uma vez que "não somente define práticas institucionais, como também serve para construir nosso senso de nós mesmos - nossa subjetividade".

Em nosso trabalho como educadora de professores de línguas, temos nos valido, prioritariamente, de autobiografias em cursos de formação inicial e continuada, com o intuito de levar os participantes a conhecerem sua identidade acadêmico-profissional e, então, refletirem sobre os fundamentos que orientam sua prática docente. As pessoas que escreveram suas autobiografias em nossos cursos são geralmente estudantes de Letras ou de cursos de pós-graduação, que narram como aprenderam a língua adicional alvo no Brasil, trazendo, para seus textos, personagens, impactos, sentimentos e efeitos dessa trajetória de aprendizagem.

Essa abordagem, distinta da pesquisa tradicional que enfoca processos de aquisição de vocabulário, gramática ou habilidades comunicativas, traz para o centro da arena o indivíduo real, com suas emoções, sentimentos, efeitos no corpo e em suas relações sociais, ou seja, aspectos íntimos que permeiam o percurso de aprendizagem de uma outra língua, conforme pontua Kramsch (2012). Insere-se, portanto, numa crescente tendência na área de Linguística Aplicada em nosso país, com contribuições expoentes como, por exemplo, as de Barcelos (2006; 2017), Paiva (2008; 2017), e, no exterior, como as de Norton (2012), Kramsch (2012) e Block (2007), que se voltam para a investigação da identidade do docente de línguas.

A autobiografia discutida neste artigo, diferentemente das anteriores sobre as quais refletimos em outras publicações (Romero, 2010; Chiulli e Romero, 2016, por exemplo), é particularmente peculiar porque tematiza com vivas cores momentos de grande carga emotiva vivenciados por um brasileiro, imigrante nos Estados Unidos durante sua adolescência, esforçando-se para inserir-se na nova cultura escolar e social, ao mesmo tempo em que aprendia, no dia-a-dia, o novo idioma. O texto que nos serve de corpus foi elaborado anos após os 
acontecimentos narrados, quando o narrador já estava de volta ao Brasil, cursando Letras. Mesmo assim, logra transportar-nos para os acontecimentos conforme vistos por sua ótica, envolvendo-nos nos sentimentos, terreno de desencontros e angústias experimentados no processo.

Objetivando direcionar a análise e interpretação dos dados, as seguintes perguntas de pesquisa foram elaboradas: (a) Como o narrador avalia seu processo de aprendizagem da língua e inserção na cultura alvo?; (b) Há exemplos de agência? (c) Como o narrador avalia sua prática docente?; (d) Como as avaliações se caracterizam linguisticamente, de acordo com o Sistema de Avaliatividade?

Antes de analisar excertos da autobiografia, trazemos conceitos que fundamentam nossas interpretações, a saber, identidade do docente de línguas, agência e o papel de narrativas autobiográficas na formação de professores. Para alcançar maior profundidade na análise do texto gerado, valemo-nos de princípios da Linguística Sistêmico Funcional, especificamente do Sistema de Avaliatividade (Martin e White, 2005), com o intuito de compreender as avaliações presentes na narrativa. Entendemos que, dessa forma, será possível refletir sobre esses significados conforme construídos na linguagem e suas implicações no processo de formação docente.

Fechamos o artigo compartilhando reflexões sobre o estudo, destacando o desenvolvimento de identidade docente, o aporte linguístico do Sistema de Avaliatividade e implicações para o educador.

\section{Identidade do Docente de Línguas e o Papel de Autobiografias}

A identidade do professor, pontua Nóvoa (2000) em elaboração seminal, é um processo histórico e contextual de contínua construção, pautado por lutas e conflitos decorrentes dos sentidos que damos a fatos e personagens que estão ou estiveram em nosso percurso.

Mais recentemente, Barkhuizen (2017: 4) ecoa os dizeres do autor português, trazendo um tom ainda mais complexo inerente à identidade do professor de línguas. Para o educador neozelandês, o docente que se dedica ao ensino de línguas se depara com uma intricada variedade 
de aspectos, frequentemente contraditórios. Isso se dá porque lida com fatores que, além de históricos, dinâmicos, interacionais e contextuais, são igualmente "cognitivos, emocionais, sociais, ideológicos, localizados tanto em si mesmo quanto no mundo social, material e tecnológico". Ademais, o autor observa que a identidade desse profissional é esculpida na linguagem e pela linguagem, demandando, por conseguinte, grande capacidade de negociação. Sendo um ofício estruturado pelo uso da língua, evidencia-se no agir e no relacionar-se com outros. As tensões pelas quais passa têm a vantagem de impulsionar o professor de línguas para constante evolução, principalmente por dele se exigir que se adapte a diferentes materiais didáticos, sejam eles físicos ou online.

É importante lembrar, apoiando-nos em Moita Lopes (2002), que a escola tem primazia em nossa constituição como seres sociais, uma vez que é, principalmente lá, quando ainda crianças, que aprendemos a nos relacionar com outros e a nos expor, a nos arriscar. Isso acentua o fato de que nossa identidade é construída socialmente desde muito cedo, sendo o ingresso no ambiente escolar responsável por dinamizar e provocar novas percepções de nós mesmos e do mundo em que estamos inseridos.

Apoiando-nos em Norton (2012), devemos ainda acrescentar que, além de sua natureza dinâmica e dependente de contingências contextuais, a identidade não é somente dada por estruturas sociais, mas também resultante de negociações sociais que fazemos sobre como desejamos nos posicionar no presente e projetar nosso futuro. Aí imbricado, está o conceito de agência, que vem ocupando cada vez mais espaço em nossa área, a partir de distintos enfoques teóricos.

Segundo Huang (2013), apoiado em discussões advindas da teoria social, ressaltadas especialmente por Giddens, em 1976, agência está relacionada à intervenção visando a objetivos específicos, e provoca efeitos ou mudanças em eventos do mundo. Isso implica que o agente tem a capacidade de, mesmo inconscientemente, analisar e avaliar o contexto social de modo a entender poderes envolvidos e a agir juntamente e sobre os influenciados por esse poder. É, conforme destaca o educador, uma capacidade de ação que se realiza em interação com o meio social e cultural em que está imersa, também desse meio dependendo sua interpretação. 
O autor chinês traz elaborações neovygotskyanas expressas em Lantolf e Thorne (2006:238), segundo as quais a agência não pode ser considerada uma característica própria de um indivíduo, posto que constantemente se reconstrói em negociações com outros e com a sociedade em que o agente está inserido. Nesse viés, os dois educadores salientam um princípio básico da teoria da atividade, que traz a mediação para o centro da questão, uma vez que "a agência é sempre e em qualquer lugar restrita por agrupamentos sociais, recursos materiais e simbólicos, contingências situacionais, capacidades de um indivíduo ou de um grupo, e assim por diante" (tradução nossa) ${ }^{4}$.

Com posicionamento semelhante, Aro (2016) explica que o aprendiz pode ser considerado agente quando toma iniciativa, participa de e realiza ações. Acentua que um agente "participa em diálogo com seu meio ao perceber, sentir, experienciar, contribuir, falar e agir por inteiro e por toda sua vida (...) [e] está completamente ligado a seu meio e especialmente à inevitável presença de Outros (2016:49)" (tradução nossa $)^{5}$.

Mais recentemente e inscrevendo-se no enfoque da teoria da atividade, assim como Lantolf e Thorne, Ninin e Magalhães (2017) destacam a natureza colaborativa em atividades coletivas que estão pressupostas no conceito de agência individual, uma vez que o agente considera e enfrenta conflitos contextuais, mas cria possibilidades que possam transformar seu meio. Segundo as autoras, o agente não se restringe a ações conscientes e deliberadas, mas leva em conta necessidades e interesses de outros. Para tanto, o agente, orientado para conseguir transformações para si ou para seu grupo, evidencia tanto habilidade no uso de ferramentas práticas e conceituais quanto criatividade para lidar com regras e relações sociais. Tal característica pode implicar questionamento, enfrentamento e transgressões em relação a sentidos e significados estabelecidos socialmente.

4. No original: Agency is always and everywhere constrained by social groupings, material and symbolic resources, situational contingencies, an individual or group's capabilities, and so on. (Lantolf e Thorne, 2006:238).

5. No original: $[\ldots]$ participates in dialogue with his or her environment by perceiving, sensing, experiencing, contributing, speaking, acting (...) is inextricably linked to his or her environment and especially to the inevitable presence of Others. (Aro, 2016:49). 
Sustentando esse enfoque, Benson (2017) lembra que a relação entre identidade docente e agência tem sido recente, à medida que o conceito de "agência" vem sendo preferido, em detrimento de "autonomia". Essa preferência, para o educador, deve-se a elaborações teóricas socioculturais, que entendem o termo "autonomia" como ligado à ideia ilusória de que o indivíduo teria controle irrestrito sobre sua própria vida, contrariando a condição social do ser humano. Contudo, Benson observa que, frequentemente, as análises de dados apresentadas nos estudos sobre identidade docente mostram ações que vão na contramão de restrições sociais, o que reforça a argumentação de que o exercício da agência condiciona-se a contextos situacionais. Colocando de outra forma, o autor recorre a uma publicação de Glas (2015, apud Benson, 2017:22), para quem “o indivíduo não 'tem’ agência, mas a agência é 'realizada' em contextos situacionais".

Ademais, conforme advoga Barcelos (2017), importa salientar que o agente é uma pessoa genuína, envolvido em interações reais, também compostas de emoções, valores e conceituações.

Assim, pode-se compreender como a agência coloca-se como uma resposta ou reação que aprendizes bem sucedidos de línguas adicionais têm frente a obstáculos e oportunidades contextuais que se apresentam.

Considerando que este estudo tematiza o processo de aprendizagem de inglês no próprio país da língua foco, torna-se especialmente importante, ainda, atentarmos para esse contexto específico. Block (2007: 75) sustenta que os aspectos culturais são especialmente relevantes; em outras palavras, há uma relação estreita entre aprender uma língua e integrar-se socialmente na cultura alvo. Nessa perspectiva, quando a identidade é construída em contextos de migração, os conflitos vivenciados pelo sujeito veem-se ainda mais acirrados. Nas palavras do autor:

(...) é na experiência migrante do adulto que a identidade e o próprio sentido de 'self' são mais colocados à prova, não somente porque a maioria ou todos os sistemas de apoio em termos de história, cultura e língua foram removidos e precisam rapidamente ser substituídos por outros novos. É no turbilhão resultante desse relativo vácuo que os indivíduos são forçados a se reconstruírem e se redefinirem, tanto pelo seu próprio sentido ontológico 
de segurança, quanto pelas posições atribuídas a eles por outros em seus novos ambientes ${ }^{6}$.

Tal postulação nos leva a ponderar que, se para o adulto a migração traz tanta insegurança, no caso de criança e adolescente, conforme focalizado em nosso estudo, o estado de confusão ao se ver em outra configuração cultural não pode ser tão distinto. Pressupomos que, nesse período, ainda há grandes fragilidades quanto a referências sociais, além do que crianças e adolescentes ainda são geralmente dependentes de apoio e buscam mais ansiosamente se verem inseridos no meio em que habitam.

Considere-se, em acréscimo, que nossa história de vida, principalmente por ser filtrada singularmente pela forma como a interpretamos, produz saberes e modos de ser e de estar no mundo. Nessa perspectiva, destaca Nóvoa (2000: 17), "é fundamental fazer com que os professores se apropriem dos saberes de que são portadores e os trabalhem do ponto de vista teórico e conceptual". Seguindo na mesma direção, Celani (2004) advoga ser crucial que as representações que nos guiam sejam compreendidas e integrem a formação docente, pois, conforme já pontuava Moita Lopes (2003: 31), "não se pode transformar o que não se entende". Ou seja, para que novos conhecimentos e pensamento crítico se desenvolvam, há que se ter como ponto de partida os conhecimentos já internalizados que podem ser alicerces de referência para o (futuro) professor.

Consequentemente, a narrativa autobiográfica tem sido um instrumento frequente, utilizado desde a década de 70 na formação de professores, dado seu potencial de levar o (futuro) profissional a entender as razões e os significados que o construíram até então e, a partir daí, refletir, de maneira informada, em interação com teorias sistematizadas. Conforme argumenta Nóvoa (2000), a utilização de autobiografias torna possível que elaborações teóricas desenvolvam-se por meio da

6. No original: is in the adult migrant experience that identity and one's sense of self are most put on the line, not least because most or all previous support systems in terms of history, culture and language have been removed and must rapidly be replaced by new ones. It is in the maelstrom resulting from this relative vacuum that individuals are forced to reconstruct and redefine themselves, both for their own sense of ontological security and the positions ascribed to them by others in their new surroundings. (Block, 2007:75). 
discussão de conhecimentos assistemáticos que cada (futuro) professor traz consigo, gerados historicamente. Infere-se, portanto, que o uso de narrativas (auto)biográficas contribui potencialmente para que a formação docente desenvolva-se com base dialética, afastando-se do dogmatismo de prescrições normativas acríticas. Com esse proceder, a prática interage dialeticamente com a teoria, parafraseando Freire (1996). Novos saberes, por conseguinte, são edificados em bases pertinentes e significativas para o professor em desenvolvimento inicial ou continuado.

Para Souza (2016), a abordagem biográfica é de especial valia na formação docente porque investe na pessoa do professor, faz com que sua voz seja protagonizada, à medida que traz experiências e aprendizagens lapidadas ao longo de sua vida. A narrativa (auto)biográfica possibilita entender significados integrantes da identidade profissional que foram se cristalizando com o tempo e pautando formas de agir e de relacionar-se com a docência. Configurando-se como um processo de conhecimento, pontua o educador, a abordagem biográfica, quando integra o processo educativo, realiza o intento de levar o licenciando ou professor a informar-se e formar-se, calcando-se no entendimento dos significados que ele próprio teceu ao longo de sua história.

Em síntese, nosso entendimento acerca de autobiografia é que se trata de uma história de nós mesmos que relembramos, em vista de contingências contextuais, e contamos para nós mesmos e/ou compartilhamos com outros, o que pode resultar em melhor auto-compreensão. Essa narrativa, notadamente no âmbito da formação acadêmico-profissional, pode impulsionar reflexões e dar acesso a novos paradigmas.

Explica-se, assim, o interesse de tantos educadores brasileiros, dentre os quais Telles (1999; 2004), Barcelos (2002; 2006), Paiva (2007; 2008), Mello (2007; 2012), Ferreira $(2009 ; 2015)$, para citar apenas alguns autores e algumas publicações, em tomar a (auto)biografia como objeto de seus estudos.

Complementando com as palavras de Bruner (1998: 33), a autobiografia imprime especial valia ao processo de formação: para “(...) entender o ser humano é preciso entender como suas experiências e atos são moldados por seus estados intencionais [e] (...) a forma desses estados intencionais é realizada por meio da participação nos sistemas 
simbólicos da cultura"7 Tendo em conta que, além de nos fundamentarmos em conceitos de identidade do docente de línguas, de agência e do papel de narrativas autobiográficas no processo de formação de professores, também nos debruçamo sobre o texto produzido e passamos, a seguir, a discorrer sobre princípios fundantes da Linguística Sistêmico-Funcional, em especial sobre o Sistema de Avaliatividade, o instrumento de análise linguística aqui utilizado.

\section{Conceitos Chave da LSF e o Sistema de Avaliatividade}

Conforme lembram Fuzer e Cabral (2014), a Linguística Sistêmico-Funcional (LSF) tem sua origem nos estudos do antropólogo Malinovski, para quem a língua é, por excelência, uma manifestação cultural de um povo. Tomando a concepção de que língua é intimamente ligada ao seu uso contextual, Firth começou a expandir seus estudos nessa direção, seguido por Halliday, que desenvolveu a nova abordagem linguística a partir da década de 1960, sistematizando suas bases e operacionalidade em 1985. Desde então, vários outros desdobramentos se seguiram, despertando interesse de estudiosos em todos os continentes.

A denominação Sistêmico justifica-se pelo entendimento de que a língua é formada por sistemas linguísticos conectados que formam uma rede de relações. O termo Funcional refere-se à função de atender às necessidades do ser humano, valendo-se de estruturas que também contribuem para construir significados.

ALSF enfoca o uso da língua, respeitando o contexto social em que ela ocorre. Por esse motivo, a língua viva é seu objeto e é caracterizada por fatores como situação, usuários socialmente localizados, objetivos, temporalidade etc. Assim, o ambiente e o contexto de realização do texto, seja ele escrito ou oral, são cruciais, uma vez que a linguagem é tida como socialmente motivada.

7. No original: “(...) to understand man you must understand how his experiences and his acts are shaped by his intentional states, (and) (...) the formo $f$ these intentional states is realizes only through participation in the symbolic systems of culture". (Bruner, 1998:33). 
Cabe esclarecer que, diferentemente da gramática tradicional, que se organiza em torno de um enfoque sintático, a LSF tem base semântica, ou seja, identifica o papel de vários itens linguísticos em qualquer tipo de texto e sua função na construção de significados.

Um dos mais destacados princípios da LSF é que fazemos escolhas gramaticais, lexicais e de organização textual quando escrevemos ou falamos. Essas escolhas carregam consigo significados atribuídos pelo escritor ou falante em referência às relações interpessoais, bem como a sentidos atribuídos à sua experiência e ao entendimento do mundo. Tal característica implica diretamente a materialidade do texto, dando âncora a intuições interpretativas.

Dentre os vários ramos que a teorização hallidayana originou, ocupamo-nos aqui do Sistema de Avaliatividade que, derivando da gramática de significados interpessoais, objetiva oferecer ferramentas linguísticas para que entendamos mais a fundo como avaliamos pessoas, entidades, eventos, situações etc., além de indicar como negociamos em relações sociais. Desse modo, o instrumental linguístico proposto visa a aclarar compreensões referentes a subjetividades, posicionamentos, envolvimentos, valores, emoções, afiliações, enfim, identidades construídas em textos (Martin e Rose, 2005). Daí tal sistema alinharse ao propósito deste estudo, voltado ao entendimento do processo de construção identitária do professor de línguas.

Gramaticalmente, as avaliações podem estar codificadas explicitamente nos textos em estruturas diversas, como em qualidades em orações relacionais (por exemplo: Inglês não é difícil), em epítetos de grupos nominais ( $A$ inusitada apresentação do coral), em nominalizações (A coragem demonstrada), em circunstâncias (Ela saiu alegremente) ou, ainda, em processos utilizados (Eles choraram juntos.) (Almeida e Vian Jr., 2018; Martin e White, 2005). Mas cabe lembrar que avaliações também são realizadas de forma implícita, quando não se pode precisar a palavra ou expressão que carrega o elemento avaliativo.

O Sistema de Avaliatividade abrange três domínios: Engajamento, Gradação e Atitude. Por meio do Engajamento podemos identificar como o falante ou escritor se posiciona ante outros ou ante a questão tematizada em trocas sociais, ou seja, como ele se aproxima ou se 
distancia do que é dito ou escrito, como se afilia a valores ou crenças de determinadas comunidades. A Gradação, por sua vez, oferece mecanismos para que diferentes graus de força (intensidade e quantidade) e foco (precisão) nas realizações linguísticas sejam evidenciados.

O subsistema de significações denominado Atitude, considerado o principal por Martin e White (2005), configura-se como mais adequado ao propósito aqui enfocado, por isso o detalhamos.

Lançando mão da estrutura Atitude, podemos mapear a construção de sentimentos conforme realizados em textos que produzimos. Para abarcar suas regiões semânticas, há três subdivisões que se relacionam a emoção (Afeto), ética (Julgamento) e estética (Apreciação). O Afeto refere-se a sentimentos ou emoções negativos ou positivos de felicidade, satisfação e segurança, como, por exemplo, em Gostei de sua iniciativa. O Julgamento atenta para como consideramos comportamentos de outros no que concerne à ética e à moralidade geradas por instituições sociais, conforme pode-se perceber em Não é certo votar pelo aumento do próprio salário. Enquanto Afeto e Julgamento dizem respeito a pessoas, a Apreciação indica como avaliamos objetos, fenômenos, desempenhos ou instituições quanto a seu valor, beleza, qualidade etc. A frase O quadro ficou lindo! ilustra a Apreciação.

Considerando que nosso corpus é uma autobiografia e que as perguntas de pesquisa que nos orientam visam ao exame de autoavaliações frente a questões processuais em três níveis de atuação, a saber, aprendizagem de uma nova língua, agência e prática docente, a expectativa é que as avaliações realizadas se identifiquem no âmbito do Afeto. É bem verdade que tanto Julgamento quanto Apreciação também podem trazer à tona significados para a discussão da identidade do professor, mas, nesta investigação, limitamo-nos a considerar construções linguísticas indicativas de emoções do narrador. Tal decisão acentua-se com duas asserções fulcrais. A primeira é de que o afeto é um recurso semântico para construir emoções. A segunda é destacada na explicitação de Almeida (2010: 44-45), para quem “... o afeto revela a personalidade humana, descortinando informações sobre a sua ideologia e as crenças". Levando-se essas pontuações em conta, a tarefa a que nos propomos aqui é também verificar se a análise linguística dos dados é coerente com as interpretações feitas à luz dos conceitos teóricos anteriormente citados. 
Antes, porém, há que se explicitar o percurso teórico-metodológico empreendido.

\section{Aporte Teórico-Metodológico}

Além de fértil instrumento para deflagrar reflexões, como já argumentado, a narrativa autobiográfica ainda compartilha aspectos do mundo social segundo a ótica de quem está nele inserido. A voz do narrador, assim, não somente é trazida para o centro de debates acadêmicos, mas também carrega consigo pequenos cosmos da sociedade, com grande riqueza de elementos contextuais que a compõem. Esse protagonismo do sujeito em formação e o interesse em se pesquisar itinerâncias peculiares com vistas à reflexão é a base da pesquisa biográfica, pois que provoca tanto no narrador quanto em leitores interessados, por meio de aprendizagem vicária, "questionamento retroativo e prospectivo sobre seus(s) projetos)s) de vida e sua(s) demanda(s) de formação atual" (Josso, 2010: 71).

A autobiografia, argumenta a autora francesa, utilizada como instrumento que articula pesquisa e formação, leva a uma revisão fundamentada de experiências e, sobretudo, dos significados construídos daí decorrentes. Colocando de outra forma, esse processo potencialmente resulta em ressignificações que dão acesso a novos paradigmas pessoais e profissionais.

Por levar em conta tais perspectivas, em que se acentua a observação de um mundo particular que espelha práticas sociais contextualizadas, acopladas a significados construídos por seu observador e ator, o estudo se insere no rol de pesquisas qualitativas (Bortoni-Ricardo, 2008).

Especificamente, o corpus é uma autobiografia elaborada pelo participante-narrador durante o primeiro ano do curso de Letras, em 2013, em uma universidade pública do sul de Minas Gerais. A educadora-pesquisadora instruiu o então estudante a rememorar processos de aprendizagem da língua inglesa, bem como sua relação com as respectivas formas de ensino-aprendizagem que vivenciou com a língua alvo. 
Cabe esclarecer que o participante-narrador, hoje já formado há três anos, escreveu a autobiografia no início de sua formação inicial. Anteriormente, havia vivido cerca de dez anos nos Estados Unidos, com seus pais, brasileiros de Minas Gerais, de origem simples e poucos recursos, que para aquele país imigraram em busca de melhores perspectivas econômicas, sociais e culturais. Assim, a maior parte do ensino básico foi cursada pelo participante-narrador em escolas públicas americanas.

O texto produzido foi categorizado de modo a responder as três primeiras perguntas de pesquisa que, por sua vez, foram consideradas à luz de conceitos de construção da identidade do professor de línguas e agência. Os excertos selecionados para este artigo, devido à restrição de espaço, são os considerados pela pesquisadora como os mais significativos, embora o anexo possa fornecer mais elementos para o leitor interessado. Buscamos, também, comprovação linguística das interpretações por meio de instrumentais do Sistema de Avaliatividade.

O próximo item traz nossas interpretações, organizadas de acordo com as perguntas de pesquisa, definidas no início deste trabalho.

\section{Avaliações nos Processos de Aprender e Ensinar Língua e Cultura}

As discussões nesse item seguem as perguntas de pesquisa. Assim, examinamos primeiramente as avaliações construídas pelo narrador referentes a seu processo de aprendizagem de inglês, enquanto vivia nos Estados Unidos. Complementarmente, exemplos de agência são discutidos. Na sequência, voltamos a atenção para as avaliações relativas à prática docente. As marcas de avaliatividade, que nos permitem ter mais precisão sobre a interpretação dos itens avaliativos, são apontadas à medida que interpretamos os excertos selecionados.

A autobiografia é iniciada com uma descrição de uma rotina de sala de aula, ocorrida no máximo dois meses depois que o narrador havia entrado na escola. A professora pede aos estudantes da sala que leiam o que está no quadro e identifiquem os erros. Pode-se perceber, no excerto abaixo, o esforço do aprendiz para se integrar aos outros - 
falantes nativos - e como buscava orientar-se, pelo pouco que sabia, raciocinando com base em experiências anteriores, para poder participar do desafio colocado:

The rest of the class got up and I followed suit.(...) I didn't get much; some words here and there, and what I thought to be possible mistakes. (...) I had figured out mistakes tended to repeat.(...) But I was meek, unsure and doubtful of my own knowledge. It made me feel nervous. (...) Get something right made me swell inside, made my heart skip with surprise. I felt less inferior. I was less distrustful of myself, and there was a resemblance of ground under my feet.

Todo o empenho descrito é acompanhado por marcas linguísticas de emoção, como as negritadas, que podem ser interpretadas como Afeto de Insegurança, dentro do subsistema de Atitude. O autor nos transporta para as nuances dolorosas do processo de inserção que vivenciou ainda tão jovem (But I was meek, unsure and doubtful of my own knowledge. It made me feel nervous. (...) I felt less inferior. I was less distrustful of myself, and there was a resemblance of ground under my feet.), mostrando como, teimosamente, tateava à procura de indícios tanto na linguagem (I didn't get much; some words here and there...) quanto na cultura (The rest of the class got up and I followed suit.) para se integrar no novo contexto.

Na continuação da narrativa, é dado o erro que agravou o estado de confusão do narrador. De acordo com o que consta geralmente em livros de ensino-aprendizagem de língua inglesa para iniciantes, conforme o leitor há de se recordar, o nome de mulheres casadas é precedido de Mrs. e o de solteiras de Miss ou Ms. Essa regra o narrador, então menino, já havia elaborado. Mas a regra simplificada não encontrou confirmação no significado ideológico compartilhado pelos demais, uma vez que o uso de Ms. nos Estados Unidos da América indica que a mulher em questão não deseja ser definida pelo seu estado civil. A insegurança, então, é intensificada, visto que nem o entediado tradutor (na voz do autobiografado) que deveria auxiliá-lo nas aulas, nem a professora americana ofereceram explicação que esclarecesse o fundamento cultural que justificava a exceção, apesar de o autobiografado querer negociar, querer aprender, como se pode deduzir na agência expressa na frase I told him it was, na sequência abaixo:. 
I waited for someone to correct it, but the moment never came. So I raised my hand. (...) I had seen Miss and Mrs., but Ms. was foreign. She was married after all and the rule was simple. I crossed out the Ms. (...) My translator looked at me, bored, and said it wasn't a mistake. I told him it was. My translator said "Ela prefere $M s$. ."

A derrota é recuperada na memória com claras evidências da frustração, pois mostra o desalento de perceber que a meta tão desejada de pertencimento por meio da língua parecia inatingível. Gramaticalmente, tem-se uma Atitude de Afeto indicativa de Infelicidade na descrição do efeito gerado pelo insucesso da iniciativa arriscada:

I took the bathroom pass, went out into the hall and sat curled up against the wall. I didn't cry. I didn't feel sad. I felt what everyone learning a language eventually feels: defeated and hopeless. To sense that it's coming together, that you have found some direction to go in, only to then find out it's not going to be that easy can be disheartening. It can establish a perception of inferiority to native speakers. Learning a language involves making flubs; embarrassing, mortifying flubs that can leave you with the idea that natives know all, and that you're never quite going to be on their level. (...) I would always trust natives over my own better judgement. (...)

A dor do processo de aprendizagem em ambiente natural parece ir diretamente ao encontro das colocações de Barcelos (2006; 2017), Kramsch (2012), Norton (2012) e Block (2007). As fortes emoções que integram toda experiência de aprendizagem, as sucessivas tentativas e erros sempre associando-se a grandes riscos, o raciocínio presente na busca de coerência entre regra e uso, bem como o desejo de pertencimento, o constante embate interno e externo de afirmar-se socialmente, a desestabilização da harmonia, a procura de uma nova identidade satisfatória para si e aceitável para os outros já instalados no contexto almejado estão todos representados nos excertos acima. É, assim, que crenças e emoções são desafiadas todo o tempo, como escreve Barcelos (2017).

Por outro lado, há também claros indicativos de agência, conforme conceituados por Lantolf e Thorne (2006), Huang (2013), Aro (2016) e Ninin e Magalhães (2017), uma vez que, apesar de toda a insegurança, o aprendiz arrisca-se, engaja-se socialmente e participa da interação em 
curso, como expresso nos excertos acima, quando decide, calcando-se em seu raciocínio, mostrar um erro (o uso de $M s$., ao invés Mrs.) nos exemplos apresentados à sua classe.

Há outras iniciativas tomadas para superar as limitações que percebe e que têm como propósito sua inserção social, uma vez que o menino imigrante quer ser visto pelos colegas de classe e professores de modo diferente, gerando, assim, transformação no seu status social. A busca de inserção social remete à observação de Aro (2016), para quem a agência está diretamente vinculada ao meio e, particularmente, ao efeito que se quer causar em outros. Além disso, conforme se pode observar no excerto a seguir, o narrador menciona que lança mão de ferramentas práticas que tem a seu dispor, como gravador e dicionário online, para melhorar sua pronúncia e, dessa forma, poder participar da atividade social coletiva, a peça de Shakespeare. Pode-se inferir que essa ação relaciona-se às características típicas de agência de um sujeito, conforme indicado por Ninin e Magalhães (2017). As iniciativas são construídas na linguagem como Afeto de Insegurança (feeling of inferiority), como se vê em:

It's because of this feeling of inferiority that I would spend hours practicing for a presentation in high school, or would record myself reading whatever part of the Shakespeare play I had to read the next day and practice until my pronunciation was perfect (which would include comparing it to the pronunciation of an online dictionary).

No que tange à prática docente, igualmente temos avaliações que salientam a criticidade do narrador e sua consciência de como mudava suas concepções e consequente agir em sala de aula e com seus alunos em função da necessidade deles, o que aponta para flexibilidade ante contingências situacionais e reconstrução resultante de negociação com outros e o meio, destacadas tanto por Lantolf e Thorne (2006) quanto por Benson (2017).

O exercício de professor-narrador enfoca dois momentos distintos, sendo o primeiro quando o narrador ainda se encontrava nos Estados Unidos e dava aulas para imigrantes, e o segundo momento já no Brasil. 
No primeiro momento, ressalta-se como ele estava ciente de sua falta de preparo profissional adequado e inexperiência, resultando linguisticamente em Atitude de Afeto de Insatisfação:

When I started teaching English I felt less than qualified. (...) I don't think what I did then was even teaching. (...) I followed the book. The book knew best. Suffice to say, it didn't quite work.

My frustration grew seeing that the students actually enjoyed my classes. It was odd. I felt the praise was unearned. Cheap.

A meta de ser bem-sucedido, mesmo sabendo-se inadequado, mais uma vez coaduna-se com a concepção de Barkhuizen (2017) e Nóvoa (2000), isto é, o conflito com o estado emocional e cognitivo colocado em questão quando ele vê desarmonia entre a reação positiva dos alunos e o desacordo com as aprendizagens construídas por suas experiências de vida. Tem-se a impressão que, naquele primeiro momento, o autobiografado tinha como premissa que para ser professor era necessário seguir o livro, o que agora, ao rever suas ações pedagógicas, avalia como ineficiente.

Na tentativa de explicar o bom resultado, embora não esperado, manifesta-se a agência, traduzida novamente em dedicação e envolvimento, visando a melhores resultados para os alunos, transformação do contexto e atendimento a contingências, um traço característico da agência, conforme identificado por Ninin e Magalhães (2017) e Benson (2017). Note-se que há empatia por parte de alguém que já esteve no lugar daquele que não sabe e precisa superar severas dificuldades:

Looking back, I think they liked my classes because I cared. I wanted them to learn. I needed them to learn for my own personal well-being. I was invested because I knew their struggle; they were immigrants. They were me. They were my parents. They were people who couldn't go to a hospital by themselves.

Interessante constatar que, agora, o Afeto reflete Satisfação, aliado ao sentimento de identificação com as necessidades do outro, com base em sua própria vivência. A avaliação, portanto, é de um espelhamento: ele olha para os alunos imigrantes como se fossem ele mesmo no recente passado. Eles são o que ele era, por isso os compreende e com eles se 
identifica. E essa identificação pode ser a justificativa da empatia e do sucesso alcançado entre seus aprendizes imigrantes.

O indicativo de Satisfação e Segurança ilustrado no excerto abaixo é acentuado, pois o narrador decide, já de volta ao Brasil, proceder em suas aulas o que lhe ditou a aprendizagem de inglês pela vivência pessoal e a experiência inicial de professor, ou seja, não seguir cegamente o livro didático, mas adaptá-lo às necessidades de seus alunos, bem como privilegiar o uso da língua, não sua forma, conforme expresso no excerto:

I was surer of myself this time around. The book wasn't going to control me. The instructions were to follow the book, but I didn't do so. I had to adjust it to the individual classes.

I learned how to correct a student, how to lead a student to an answer (...) necessary is to understand not just the structure of a language, but the culture in which that language exists to grasp the use of said language.

A transformação identitária do narrador-professor, percebida ao compararmos as primeiras experiências como professor e o que mostra o excerto acima, é notória. Inauguram-se novos paradigmas, ecoando uma vez mais Barkhuizen (2017) e Nóvoa (2000), ao destacarem a marca dinâmica da formação docente. Essa nova e mais segura conceituação sobre o papel do professor de línguas é expressa em novas formas de agir na prática docente e marcada linguisticamente pela assertividade (como em: The book wasn't going to control me. (...) I didn't do so. I had to adjust it to the individual classes.) com que o autobiografado fala sobre procedimentos agora valorizados não só por ele próprio quanto também pelo novo contexto acadêmico em que está se inserindo, por meio do curso de Letras. Apesar de não haver menção, na narrativa, que o curso universitário foi o responsável por seu proceder docente mais recente, é possível que o fato de a autobiografia ter sido escrita durante o curso de Letras, enquanto o participante-narrador preparavase em um curso especial de formação para ingressar como bolsista no Programa Inglês sem Fronteiras, tenha tido um papel influente.

Em síntese, respondendo às perguntas de pesquisa especificadas no início deste artigo, o narrador avalia seu processo de aprendizagem de inglês e inserção na cultura estadunidense como um processo de 
grandes desafios pessoais que lhe afetaram emocionalmente e geraram situações de insegurança, infelicidade, insatisfação, manifestando-se, inclusive, em efeitos físicos. Para superar os problemas, responde com agência, pois que as reações materializam-se em dedicação e empenho, tendo como resultado a transformação de si e um ensino mais adequado para os outros com quem interage.

As primeiras práticas docentes narradas, exercidas antes da formação acadêmica, calcaram-se na própria trajetória de aprendizagem e, por isso, geraram empatia com a dor, as emoções e a luta dos aprendizes imigrantes que, como ele, esforçavam-se para se sentirem "menos inferiores". Resultaram, consequentemente, ações de intervenção docente adequadas àquele público alvo com o qual o narrador se identificava.

Atentando-se agora diretamente para a linguagem por meio da qual pudemos observar os valores inerentes ao processo de construção identitária construídos na autobiografia, verificamos a ocorrência de uma variedade de estruturas gramaticais:

(a) Em orações relacionais, como em I was meek, unsure and doubtful of my own knowledge; I felt less than qualified

(b) Em epítetos de grupos nominais: It can establish a perception of inferiority to native speakers.

(c) Em nominalizações: My frustration grew seeing that the students actually enjoyed my classes.

(d) Em processos (grupos verbais): they liked my classes / my frustration grew / it humbles you.

(e) Em circunstâncias: I sat curled up against the wall.

Com o Sistema de Avaliatividade, que, neste estudo, opera como instrumento de triangulação para referendar nossas interpretações dos dados, vimos que as avaliações referentes ao processo de aprendizagem de língua e cultura, bem como de agência e prática docente foram realizadas prioritariamente por meio de Afeto, o indício linguístico que revela sentimentos e emoções por excelência.

Consistentemente, pudemos observar que contexto, sentimentos, emoções e realizações linguísticas caminham na mesma direção, indi- 
visivelmente, em complementação e colaboração intensa para culminar significados específicos. Tais constatações nos levam a refletir sobre o estudo, a que passamos no fechamento, a seguir.

\section{Efeitos Reflexivos}

A autobiografia que nos serve de corpus para discutirmos o processo de aprendizagem de língua adicional e também de inserção na docência é especialmente rica em detalhes que trazem à tona os conflitos e revezes que, inevitavelmente, pontuam o percurso. Acreditamos que isso se deva ao fato de, diferentemente das demais autobiografias com as quais temos trabalhado (Romero, 2010, por exemplo), esta trazer-nos relatos de uma pessoa que construiu seus saberes referentes à língua inglesa e à docência empiricamente nos Estados Unidos da América, ou seja, em contexto de imersão, por meio de interação com os falantes locais, sem instrução específica e sistemática para aprender inglês. E sua iniciação como professor também se deu porque se identificava com sua comunidade de imigrantes nos Estados Unidos.

Desse modo, o texto do qual partimos é igualmente peculiar por conseguir retratar um contexto social específico, pouco discutido ainda em nosso país, que impõe grandes demandas e conflitos identitários, conforme ilustrado por Block (2007).

Dadas essas características, a autobiografia base nos permite entender o impacto do contexto e das interações sociais vivenciadas na construção de sentidos que, nesse caso, são transportadas tanto para concepções de cultura e linguagem quanto para atuação do docente de línguas adicionais.

Para nós, pesquisadores, parece claro, também, que o processo de elaboração de narrativas autobiográficas possibilita conscientização de teorias internalizadas, uma vez que na narrativa discutida vieram à tona o histórico da aprendizagem da língua alvo e as razões, no entender do narrador, que explicam as ações docentes atuais. Consequentemente, esse recurso para deflagrar reflexões tem alto potencial, especialmente quando mediado por um par informado, como um educador de línguas adicionais, em propiciar uma revisão de conceitos informada, com uma compreensão teoricamente consiste e atualizada do que vivenciou, o 
que, por sua vez, dá novos sentidos a experiências e à construção da identidade docente.

Ademais, há que se considerar a especificidade linguística disponibilizada pelo Sistema de Avaliatividade, possibilitando, ao educador, contar com ferramenta valiosa para triangular dados e aprofundar-se nas reflexões sobre o papel da linguagem na construção identitária do docente de línguas em formação, o que embasa e ilumina possíveis caminhos de ações educativas a serem seguidas.

\section{Referências}

ALMEIDA, Fabíola A. S. D. P. 2010. A Avaliação na Linguagem: Os Elementos de Atitude no Discurso do Professor. São Carlos: Pedro e João Editores.

ALMEIDA, Fabíola A. S. D. P.; VIAN JR. Orlando. 2018. Estudos em Avaliatividade no Brasil: Panorama 2005-2017. Signótica, Goiânia, v. 30, n. 2, p. 273-295.

ARO, Mari. 2016. In Action and Inaction: English Learners Authoring their Agency. In KALAIA, Paula; BARCELOS, Ana Maria F.; ARO, Mari; RUOHOTIE-LYHTY, M. (Orgs.). Beliefs, Agency and Identity in Foreign Language Learning. London: Palgrave MacMillan.

BARCELOS, Ana Maria F. 2002. Desvendando os sentidos do discurso dos alunos. Letras \& Letras, Uberlândia, v. 18, n.1, p. 07-15.

BARCELOS, Ana Maria F. 2006. Narrativas, crenças e experiências de aprender inglês. Linguagem \& Ensino (UCPel), v. 9, p. 145-175.

BARCELOS, Ana Maria F. 2017. Identities as emotioning and believing. In: BARKHUIZEN, Gary. 2017. Language teacher identity research: An Introduction. In: Reflections on Language Teacher Identity Research. New York: Routledge. p. 1-11.

BENSON, Phil. 2017. Teacher autonomy and teacher agency. In: BARKHUIZEN, Gary. Reflections on Language Teacher Identity Research. New York: Routledge. p. 18-23.

BLOCK, David. 2007. Second Language Identities. London: Continuum.

BORTONI-RICARDO, Stella Maris. 2008. O Professor Pesquisador: Introdução à Pesquisa Qualitativa. São Paulo: Parábola.

BRUNER, Jerome. 1998. Realidade mental, mundos possíveis. Porto Alegre: Artes Médicas.

CELANI, Maria Antonieta Alba. 2004. Culturas de educação, risco e 
incerteza. In: MAGALHÃES, Maria Cecília Camargo (Org.) $A$ formação do Professor como Profissional Crítico. Linguagem e Reflexão. Campinas: Mercado de Letras. p. 37-56.

CHIULLI, Talitha H. S.; ROMERO, Tania R. S. 2016. Retalhos Alinhavados: entendendo o construir do professor. Caminhos em Linguística Aplicada (Unitau), v. 14, p. 71-85.

FERREIRA, Aparecida de J. 2009. Histórias de Professores de Línguas e Experiências com Racismo: uma reflexão para a formação de professores. Espéculo (Madrid), v. 42, p. 1-10.

FERREIRA, Aparecida de J. 2015. Letramento racial crítico através de narrativas autobiográficas, com atividades reflexivas. Ponta Grossa: Estúdio Texto.

FREIRE, Paulo. 1996. Pedagogia da Autonomia: saberes necessários à prática educativa. Rio de Janeiro: Paz e Terra.

FUZER, Christiane; CABRAL, Sara R. S. 2014. Introdução à Gramática Sistêmico-Funcional em Língua Portuguesa. $1^{\mathrm{a}}$ ed. Campinas: Mercado de Letras.

HUANG, Jing. 2013. Autonomy, Agency and Identity in Foreign Language Learning and Teaching. Bern: Peter Lang.

JOSSO, Marie Christine. 2010. Experiências de Vida e Formação. São Paulo: Paulus.

KRAMSCH, Claire. 2012. The Multilingual Subject. Oxford: Oxford University Press.

LANTOLF, James P.; THORNE, Steven L. 2006. Sociocultural Theory and he genesis of second language development. Osford: Oxford University Press.

MARTIN, James R.; ROSE, David. 2005. Working with Discourse: meaning beyond the clause. London: Continuum.

MARTIN, James R.; WHITE, Peter R. R. 2005. The Language of Evaluation: Appraisal in English. New York: Palgrave MacMillan.

MELLO, Dilma M. 2007. The Language of Arts in a Narrative Inquire Landscape. In: CLANDININ, Jean. (Ed.). Handbook of Narrative Inquiry: mapping a methodology. $1^{\text {st }}$ ed. Florida: Sage Publications Inc, v. 1, p. 203-223.

MELLO, Dilma M. 2012. A Teacher's Story of Facing the Road of Change. Polifonia (UFMT), v. 19, p. 261-279.

MOITA LOPES, Luis Paulo. 2002. Identidades Fragmentadas. Campinas: Mercado de Letras.

MOITA LOPES, Luis Paulo. 2003. A Nova Ordem Mundial, os Parâmetros Curriculares Nacionais e o Ensino de Inglês no Brasil: a base intelectual para uma ação política. In: BARBARA, Leila; RAMOS, 
Rosinda de C. G. (Orgs.). Reflexão e Ações no Ensino-Aprendizagem de Linguas. Campinas: Mercado de Letras. p. 29-57

NININ, Maria Otília G.; MAGALHÃES, M. C. C. 2017. A Linguagem da Colaboração Crítica no Desenvolvimento da Agência de Professores de Ensino Médio em Serviço. Revista Alfa, v. 61, p. 625-652.

NORTON, Bonny. 2012. Identity and Language Learning. Bristol: Multilingual Matters.

NÓVOA, António. 2000. Vidas de Professores. Porto: Porto Editora.

PAIVA, Vera L. M. O. 2007. As habilidades orais nas narrativas de aprendizagem. Trabalhos em Linguística Aplicada. v. 46, n.2, p. $165-179$.

PAIVA, Vera L. M. O. 2008. Aquisição e complexidade em narrativas multimídia de aprendizagem. Revista Brasileira de Linguística Aplicada. V.8, n.2. p. 321-339.

PAIVA, Vera L. M. O. 2017. Language teaching identity: a fractal system. In: BARKHUIZEN, Gary (Ed.) Reflections on Language Teacher Identity Research. New York: Routledge. p. 258-263.

ROMERO, Tania R. S. 2010. Autobiografias de Professores de Inglês: o entretecer de memória e narrativa na constituição da identidade profissional. In: CELANI, Maria Antonieta Alba. (Org.) Reflexões e Ações (Trans)Formadoras no Ensino-Aprendizagem de Inglês. Campinas: Mercado de Letras. p. 141-162.

SOUZA, Elizeu Clementino. 2016. Profissionalização, Fabricação de Identidade e Trabalho Docente: Alguns Apontamentos Teóricos. In: FERREIRA, Maria Cristina Faria Dalacorte; REICHMANN, Carla Lynn; ROMERO, Tania Regina de Souza (Orgs.). Construções Identitárias de Professores de Línguas. Campinas: Pontes. p. 15-32.

TELLES, J. A. 1999. A trajetória narrativa: Histórias sobre a formação do professor de línguas e sua prática pedagógica. Trabalhos em Linguística Aplicada, Campinas, SP, v. 34, p. 79-92.

TELLES, J. A. 2004. Reflexão e identidade profissional do professor de LE: Que histórias contam os futuros professores? Revista Brasileira de Lingüística Aplicada, Belo Horizonte: UFMG, v. 4, n.2, p. 57-83.

Recebido em: 22/07/2018

Aprovado em: 05/07/2019 
Anexo

The whiteboard came out.

By now, I already knew the routine. At some point in the afternoon (maybe not every single afternoon throughout the week, but at - what I believed at the time - random ones), she would bring out the board with the writing already on it, set it up, sit down beside it, and call us all to sit semi-circled on the rug in front of her.

It was D.O.L. time.

The rest of the class got up and I followed suit. We settled down on the rug, and I looked up at the board. I don't quite remember if she read the paragraph or if another student did, but I know I looked at it intently trying to get something out. I didn't get much; some words here and there, and what I thought to be possible mistakes.

By now, two or so months into an American school, I had figured out that the mistakes tended to repeat themselves. So that they're maybe had to be a there or a their; or maybe that wasn't the right your. But I was meek, I was unsure, and doubtful of my own knowledge. So looking at a paragraph and knowing that the they're had to possibly be a there or their didn't make me feel excited. It made me feel nervous. It made my neck burn with anticipation that another student would point it out and correct it. And sometimes they did.

That fact that I would get something right made me swell inside. It made my heart skip with surprise. It made me hold my breath every time the student corrected the mistake waiting for the teacher to confirm it, and when she did, it made me re-read the paragraph doubtful that I had caught the error. Maybe I was confused; maybe I had actually noticed another possible mistake and was confusing things. Then, I would finallyresignto the fact that I had been right.

By that day, I had already caught a few mistakes. As such, I felt less inferior. I was less distrustful of myself, and there was a resemblance of ground under my feet. Nevertheless, I followed my pattern when I saw that Ms. Warlone* at the end of the paragraph. Ms. Ms. M.S. I had never seen that word before. I had seen Miss, and I had seen Mrs.; but $M s$. was foreign. It was strange, and it was wrong. 
I had seen my teacher's name before, and it was always preceded by a Mrs.; she was married after all, and the rule was simple: $M r$. for men, Mrs. for married women, and Miss for single women. So what was $M s$. and why was it in front of a married woman's name? I was sure it was wrong, and my certainty grew stronger when I looked over to the teacher's desk and saw right up front her wooden nameplate: Mrs. Warlone.

I waited for someone to correct it, but the moment never came. So, I raised my hand. I could see the delight in Mrs. Warlone's face as she held the red marker out to me. I got up and walked over to the board. Crossing out the Ms., I wrote Mrs. on top of it. I turned around to see Mrs. Warlone's confused face. She turned to another student who served as my translator and said something. The boy looked at me, bored, and said it wasn't a mistake. I told him it was. Turning to her, I walked over to her desk and picked her nameplate up showing her it said Mrs.,not Ms. She then turned to my translator again and said something. He translated it:

"Ela prefere escrever Ms." She prefers to write $M s$.

I don't remember much of what happened after that. But I know that at some point I took the bathroom pass, went out into the hall and sat curled up against the wall.

I didn't cry. I didn't feel sad. I felt what everyone learning a language eventually feels: defeated and hopeless. To sense that it's coming together, that you have found some direction to go in, only to then find out it's not going to be that easy can be disheartening. It can establish a perception of inferiority to native speakers. Learning a language involves making flubs; embarrassing, mortifying flubs that can leave you with the idea that natives know all, and that you're never quite going to be on their level.

It's because of this feeling of inferiority that I would spend hours practicing for a presentation in high school, or would record myself reading whatever part of the Shakespeare play I had to read the next day and practice until my pronunciation was perfect (which would include comparing it to the pronunciation of an online dictionary). It's why I would always trust natives over my own better judgment. 
So, when I ended up in front of a classroom in 2010 teaching English I felt less than qualified. It was the summer after I graduated high school and for several personal reasons I had chosen not to go straight into college; the alternative, therefore, was to go into the work force. And speaking English in an immigrant community is a valuable skill - one you can get paid well for.

I don't think what I did then was even teaching. I followed the book. Whatever the book told me to do, I did. The book knew best. Suffice to say, it didn't quite work. My students didn't really learn; at least, not how I wanted them to. They could understand the basics: how to negate in the present, how to conjugate the third-person singular, and so on. But it would fall apart when the book did things such as explainthe pronunciation of the regular past tense by showing how sometimes the $e d$ was voiced and other times it was voiceless. The students had no idea what that meant; I had no idea what it meant. I felt like I was learning much more than they were. In school, I had never studied the structure of the language-American schools don't focus on that. English classes teach students how to read and think critically, not grammar. So I learned grammar because I had to teach grammar.

My frustration grew seeing that the students actually enjoyed my classes. It was odd. I was disgruntled. I felt the praise was unwarranted; unearned. Cheap. Looking back, I think they liked my classes because I cared. I wanted them to learn. I needed them to learn for my own personal well-being. I was invested because I knew their struggle; they were immigrants scrambling to learn a new language. They were me. They were my parents. They were people who couldn't go to a hospital by themselves-- or a courthouse, or a police station, or anywhere they needed to communicate.

Almost a year after starting that job I quit and decided to return to Brazil. I once again entered a classroom, but this time it was different. I wasn't teaching adults. I wasn't teaching immigrants who had something on the line. I was teaching teenagers in their home country.

Maybe it's because I already had a year under my belt, but I was surer of myself this time around. I already had my way of explaining some things, and the book wasn't going to control me. Seeing that the school was part of a chain, all my lessons were already done. The 
instructions were to follow the book; asks all the questions that were already there. But I didn't do so. By now, I could already identify if a question would really work. I could modify it. I learned that it wasn't a case of one size fit all; I had to adjust it to the individual classes. Nevertheless, I learned quite a bit that year: how to teach without relying on the native tongue; how to correct a student; how to lead a student to an answer. I learned how important my cultural background can be. I came to realize how necessary it is to understand not just the structure of a language, but the culture in which that language exists to grasp the use of said language.

From a timid third-grader who could only communicate by pointing to a teacher passing on a language, I've grown a lot. Learning a language in another country changes you. It humbles you. Shows you that you are not that special, and as such, makes you more empathetic. That empathy has affected my teaching; to know the struggle my students are going through makes me understand them better. I understand their doubts because they were once my own. 